\title{
Processo de reparação de lesões da córnea e a membrana amniótica na oftalmologia
}

\author{
Repair process of corneal damage and the amniotic membrane in ophthalmology
}

\author{
Kelly Cristine de Sousa Pontes ${ }^{*}$ Andrea Pacheco Batista Borges $^{\mathrm{I}}$ Renato Barros Eleotério $^{\mathrm{I}}$ \\ Lukiya Silva Campos Favarato ${ }^{\mathrm{I}}$ Tatiana Schmitz Duarte ${ }^{\mathrm{I}}$
}

\section{-REVISÃO BIBLIOGRÁFICA-}

\section{RESUMO}

Os eventos que fazem parte do processo de reparação de lesões da córnea ocorrem simultaneamente e envolvem proliferação, migração, diferenciação e apoptose celular, além da comunicação intercelular. Vários fatores solúveis, além de proteínas da matriz mesenquimal, proteoglicanos, enzimas proteolíticas e alguns tipos celulares são abordados nesta revisão, na qual explicam-se os processos de reparação de lesões superficiais ou penetrantes da córnea. A membrana amniótica, muito utilizada na cirurgia oftálmica, foi estudada por apresentar funções que colaboram com o processo de reparação. Entretanto, tais funções poderão ser perdidas quando tal tecido for submetido à conservação. Assim, torna-se importante conhecer o processo de reparação de lesões que envolvem, ou não, a córnea em toda a sua espessura e escolher a melhor forma de utilização da membrana amniótica quando ela for indicada na terapia para estas lesões.

Palavras-chave: úlcera de córnea, fatores solúveis, membrana biológica, enxerto.

\section{ABSTRACT}

The events included in the process of repair of corneal damage occur simultaneously and involve proliferation, migration, differentiation, cell apoptosis and intercellular communication. Several soluble factors, mesenchymal matrix proteins, proteoglycans, proteolytic enzymes and some cell types are covered in this review, which explains the processes of repair of corneal wounds, either superficial or penetrating. The amniotic membrane, used in ophthalmic surgery, was studied because of the contribution of its functions to the repair process. However, these functions may be lost when the amniotic membrane is subjected to conservation. Therefore, it is important to understand the repair process of lesions involving or not the entire thickness of the cornea, and choose the best use of the amniotic membrane, when it is indicated for the treatment of these lesions.

Key words: corneal ulcer, soluble factors, biological membrane, graft.

\section{INTRODUÇÃO}

O processo de reparação das lesões que afetam a córnea consiste em uma série de eventos que ocorrem simultaneamente. A integração da proliferação celular, migração, diferenciação, apoptose e comunicação intercelular envolvem proteínas da matriz mesenquimal, proteoglicanos, fatores solúveis e enzimas proteolíticas, além de alguns tipos celulares (KLENKLER \& SHEARDOWN, 2004).

Vários métodos de tratamento de lesões da córnea têm sido utilizados e, dentre os cirúrgicos, aqueles que envolvem a utilização da membrana amniótica têm merecido destaque. Esse tipo de membrana possui ação anti-inflamatória e antiangiogênica, além de atuar como ponte para migração celular, favorecendo a reparação de lesões. Estas propriedades garantem o sucesso nos tratamentos que a utilizam, entretanto, algumas delas podem ser perdidas quando a membrana utilizada não for fresca, mas conservada em algum meio.

A presente revisão aborda o processo de reparação da córnea quando ela for submetida a lesões tanto superficiais, quanto penetrantes. São trazidas as

'Departamento de Veterinária, Universidade Federal de Viçosa (UFV), 36570-000, Viçosa, MG, Brasil. E-mail: Kellycpontes@yahoo.com.br. *Autor para correspondência. 
funções e origens de cada fator solúvel, das proteínas da matriz mesenquimal, dos proteoglicanos, das enzimas proteolíticas e dos tipos celulares envolvidos nos eventos que compreendem tal processo.

Ainda, são revisados aspectos quanto às funções da membrana amniótica, quando utilizada a fresco ou conservada, em lesões da superfície ocular, dando ênfase às funções que podem ser perdidas e que devem ser levadas em consideração no momento da escolha do tratamento a ser instituído.

Processo de reparação de lesões na córnea

A variação na reparação de lesões que envolvem a córnea depende da profundidade e do tipo de lesão envolvida. No caso da profundidade, a reparação poderá ocorrer pelo deslizamento, ou migração, das células epiteliais para cobrir a área lesada, e por mitose, no sentido de reconstituir o número de células epiteliais normais (WILCOCK, 2008). Nesse processo, estão envolvidas proteínas da matriz mesenquimal, proteoglicanos, fatores solúveis, enzimas proteolíticas e alguns tipos celulares (DAYHAWBARKER, 1995a).

As principais proteínas da matriz são: a fibronectina, cujo papel principal está na adesão celular durante sua migração; a tenascina, que possui função semelhante à da fibronectina, mas está presente principalmente durante a reparação tecidual e em processos malignos; a laminina, que é parte integral da maioria das membranas basais e promove a aderência das células à membrana basal, interferindo no movimento, na diferenciação e no crescimento celular; e as integrinas, que servem como receptores para vários componentes extracelulares, dentre eles a fibronectina, a laminina e tipos de colágenos variados (DAYHAWBARKER, 1995a; CARTER, 2009). O dermatan e o queratan sulfato são os principais proteoglicanos presentes na córnea (MICHELACCI, 2003). Sua importância está na natureza hidrofílica, que mantém certo nível de hidratação tecidual e na manutenção do espaçamento e orientação das fibras de colágeno (DAYHAW-BARKER, 1995a).

Os fatores solúveis são proteínas que afetam o crescimento e a locomoção celular via receptores celulares. Eles desempenham papéis importantes na reparação de lesões envolvendo a córnea, sendo que vários de seus grupos já foram identificados. São eles as defensinas, o fator de crescimento epidermal (EGF), o fator de crescimento dos ceratinócitos (KGF), o fator de crescimento dos hepatócitos (HGF), o grupo do fator de crescimento fibroblástico (FGF), o fator de crescimento semelhante à insulina (IGF), os neuropeptídios, o fator de crescimento derivado de plaquetas (PDGF), a família do fator transformador de crescimento (TGF), que é dividida em duas subfamílias: o TGF- $\alpha$ e o TGF- $\beta$ e o fator de crescimento derivado do retinoblastoma (DAYHAW-BARKER, 1995a; DAYHAW-BARKER, 1995b; FINI, 1999; IMANISHI et al., 2000; YU et al., 2010; TANDON et al., 2011).

As defensinas são originadas pelas células inflamatórias e possuem efeito antimicrobiano, além de atuar com ação sinérgica junto a outros fatores solúveis no estímulo do crescimento celular (IMANISHI et al., 2000). O IGF e seus receptores são encontrados no epitélio e estroma da córnea e, ainda, na malha trabecular. Sua atuação consiste no estímulo da atividade mitótica e na diferenciação celular (FINI, 1999; KLENKLER \& SHEARDOWN, 2004).

O EGF é produzido pelas células epiteliais da córnea e, principalmente, pela glândula lacrimal. Ele atua na proliferação de células epiteliais e endoteliais (IMANISHI et al., 2000) e induz à migração das células epiteliais. Este fator solúvel inibe, ainda, a diferenciação terminal das células epiteliais da córnea e aumenta sua proliferação de forma dependente da sua concentração (IMANISHI et al., 2000; MÁRQUEZ et al., 2011).

O KGF possui atividade mitogênica restrita às células epiteliais. Por ser considerado um estimulador parácrino para o crescimento de células epiteliais da córnea, a aplicação tópica do KGF pode ser eficiente na regeneração epitelial e efetivo no tratamento de úlceras de córnea com perda do estroma. Sugere-se que o KGF seja produzido pelos ceratócitos e que atue nas células epiteliais pela ligação aos seus receptores (IMANISHI et al., 2000). O HGF, produzido em sua forma inativa por fibroblastos, é ativado por lesão, estímulo inflamatório ou proteases da cascata de coagulação. Quando ligado aos seus receptores, situados principalmente nas células epiteliais da córnea, o HGF atua na proliferação, na motilidade e na mudança da forma das células epiteliais, endoteliais e melanocíticas (GRIERSON et al., 2000). O FGF, que pode ser ácido (aFGF) ou básico (bFGF), é mitogênico para as células epiteliais, endoteliais e estromais. $\mathrm{O}$ aFGF tem sido detectado na membrana de Descemet e no endotélio da córnea, mas em menor quantidade no epitélio. Ele não foi encontrado no estroma. Em contrapartida, o bFGF e seus receptores podem ser encontrados nos três tipos celulares da córnea e no humor aquoso (WILSON et al., 1994).

O PDGF promove a reparação de lesões na córnea por aumentar o crescimento e a migração celular. Ele provoca um estímulo para a migração de células epiteliais, na presença de fibronectina, e para a migração de fibroblastos e ceratócitos. Também demonstrou efeito quimiotático para as células endoteliais, 
provocando a sua migração. O TGF- $\beta$ é dividido em TGF- $\beta 1$, TGF- $\beta 2$ e TGF- $\beta 3$. Os TGF- $\beta$ s, principalmente o TGF- 32 , atuam na regulação da proliferação celular corneal, inibindo a proliferação das células epiteliais de uma maneira dose dependente (IMANISHI et al., 2000) e o TGF- $\beta 1$ desempenha o papel principal na formação de cicatriz no tecido corneal adulto (TANDON et al., 2011).

As enzimas proteolíticas estão envolvidas na reestruturação tecidual. Especificamente para a córnea, existem dois grupos principais: o da proteinase serina, incluindo a plasmina e seus componentes relatados, e o das enzimas que requerem cofator metal, que correspondem à colagenase e à metaloproteinase da matriz. A primeira é responsável pela clivagem de proteínas da matriz, como a fibronectina e a laminina, e pode influenciar na migração celular. As colagenages e as metaloproteinases da matriz degradam e desnaturam o colágeno. Estas enzimas são importantes para a manutenção da transparência da córnea, pois atuam na remodelação e na organização da arquitetura original das fibras de colágeno (DAYHAW-BARKER, 1995a).

Várias citocinas inflamatórias estão envolvidas no processo de reparação de lesões da córnea. Elas e seus receptores estão presentes nas células e, quase todas, são produzidas pelas células inflamatórias. As citocinas regulam o crescimento celular da córnea e induzem à sua migração (IMANISHI et al., 2000).

Quase imediatamente após a ocorrência de uma lesão epitelial, ocorre a migração celular. Fibrina, fibrinogênio e fibronectina são secretados do epitélio adjacente para a face desnuda (WILCOCK, 1993). Leucócitos polimorfonucleares chegam até a área através do filme lacrimal e iniciam o processo de debridamento dos restos celulares (KERN, 1990). As células epiteliais que estão situadas nas margens do defeito se estendem e deslizam sobre a ferida, sofrendo mitose e restaurando a arquitetura epitelial normal. Esse processo tem início uma hora após a ocorrência da lesão e, em um tempo de quatro a sete dias, o epitélio estará completamente regenerado (KERN, 1990).

Quando a membrana basal epitelial estiver intacta, as células epiteliais podem utilizá-la para sua adesão ao estroma. Nos casos de perda da membrana basal, a reconstituição dos seus novos complexos será iniciada entre cinco a sete dias após a lesão, sendo necessárias seis a oito semanas para a sua completa reconstrução. A lesão penetrante no estroma causa a morte dos ceratócitos situados sob ela. Um coágulo de fibrina é depositado no defeito e há a formação de edema em sua volta (KERN, 1990). Em poucas horas, os neutrófilos chegam ao local e controlam a contaminação bacteriana, degradam o colágeno danificado e estimulam a fibroplasia e a vascularização pela produção de várias citocinas (WILCOCK, 1993; WILKIE \& WHITTAKER, 1997). Os ceratócitos das margens da ferida sofrem um processo de diferenciação em fibroblastos, aumentam em número por divisão e iniciam o processo de migração para a área onde houve a perda de ceratócitos (DAYHAW-BARKER, 1995b). $\mathrm{O}$ processo de diferenciação dos ceratócitos é, na verdade, a ativação destas células, situadas na área adjacente à lesão (FINI, 1999; WATSKY et al., 2010).

$\mathrm{O}$ processo de secreção de fibrilas de colágeno, realizado pelos ceratócitos diferenciados em fibroblastos, é iniciado e perdura por semanas. As fibrilas de colágeno são orientadas aleatoriamente e, finalizada a reparação, elas e os proteoglicanos (glicosaminoglicanos) são remodelados para que retornem à sua arquitetura original. Este processo é efetivado por enzimas, especificamente as metaloproteinases da matriz (DAYHAW-BARKER, 1995b), sintetizadas pelos fibroblastos (FINI, 1999). O novo colágeno secretado torna-se mais compacto, mas não consegue atingir a organização uniforme de antes, resultando em opacidade corneal permanente (KERN, 1990; WILCOCK, 1993; FINI, 1999).

Devido ao íntimo contato da membrana de Descemet com as células endoteliais, quando ocorre a perfuração da membrana de Descemet o endotélio também é atingido. As extremidades da membrana se enrolam e um coágulo de fibrina se deposita cobrindo a ferida. Em poucas horas, as células endoteliais adjacentes iniciam a migração para cobrir o defeito criado (KERN, 1990; WILCOCK, 1993). Após o recobrimento da área, as células são multiplicadas por mitose variável segundo as espécies, sendo que, nos gatos, primatas e no homem ela é limitada e, nos cães e coelhos, é bem desenvolvida (DAYHAW-BARKER, 1995b; SLATTER \& DIETRICH, 2007). As células endoteliais remanescentes recobrindo a área lesada começam a retomar seu formato original, entretanto, algumas permanecem como "células gigantes" (DAYHAW-BARKER, 1995b).

\section{A Membrana amniótica na oftalmologia}

A utilização da membrana amniótica, ou âmnion, em cirurgia oftálmica humana foi reportada pela primeira vez por ROTTH em 1940, que a aplicou na reparação de defeitos conjuntivais (PARK et al., 2008). Mesmo com os resultados satisfatórios alcançados com sua utilização, ela voltou a ser estudada e empregada somente em 1995, por KIM \& TSENG na reconstrução de córneas de coelhos após a remoção completa do epitélio. Desde então, ela tem sido indicada 
para diversas doenças oculares, destacando-se as queimaduras químicas e térmicas, a síndrome de Stevens-Johnson, a ceratopatia bolhosa, a ceratite bacteriana grave, o penfigóide cicatricial, as úlceras neurotróficas, as reconstruções conjuntivais e corneais após ressecção de tumores e em cirurgias de glaucoma para recobrir válvulas implantadas (DUA et al., 2004; SHEHA et al., 2009; MELLER et al., 2011).

$\mathrm{Na}$ Medicina Veterinária, o âmnion foi aplicado em ceratectomias penetrantes (BARROS et al., 1998), no simbléfaro, na ressecção de tumores esclerais e corneais (BARROS et al., 2005), em úlceras superficiais não complicadas (PONTES et al., 2008; KIM et al., 2009), na deficiência de células límbicas (CREMONINI et al., 2007), em queimaduras químicas (CHOI et al., 2011) e no sequestro corneal felino (PONTES et al., 2010).

O epitélio desta membrana possui funções especializadas, entre as quais se destacam efeito antiadesivo, propriedades bacteriostáticas, proteção da lesão, redução da dor, efeito na epitelização e pouca antigenicidade (AZUARA-BLANCO et al., 1999).

Este tipo de membrana biológica pode ser utilizado a fresco ou preservado em diferentes meios, tendo sido descritos a glicerina $98 \%$ em temperatura ambiente, a liofilização, o ar seco, o tratamento com glutaraldeído e politetrafluoreliteno e a irradiação (DUA et al., 2004; PONTES et al., 2010). Quando este tecidoé usado na cobertura da superfície ocular e é removido, ou quando se desprende espontaneamente, ele é referido como uma bandagem e, neste caso, a epitelização ocorre sob este. Quando ele é utilizado na expectativa de tornar-se epitelizado e incorporado ao tecido do receptor, ele será referido como um implante (DUA et al., 2004).

Quando a membrana amniótica é usada como um implante, deverá ser posicionada no local com a sua face epitelial, ou membrana basal, voltada para cima, sem entrar em contato com a superfície ocular. Já nos casos em que é requerida como uma bandagem, será posicionada com a sua face epitelial em contato com a superfície ocular, primariamente para conter a reação inflamatória enquanto a epitelização está ocorrendo sob ela (DUA et al., 2004). HAO et al. (2000) sugeriram que, nesta posição, ocorre a liberação de alta concentração de fatores anti-inflamatórios presentes no implante para a superfície ocular lesada.

$\mathrm{O}$ âmnion atua como membrana basal que suporta o crescimento do epitélio e da membrana basal corneal e facilita a migração das células epiteliais. Sua membrana basal possui colágeno tipo IV, laminina-1, laminina-5 e fibronectina, que desempenham papel importante na adesão das células epiteliais da córnea, que promovem diferenciação e que previnem a apoptose epitelial. ENDO et al. (2004) demonstraram, pela imunohistoquímica, que a membrana basal deste tecido e a da córnea possuem colágeno do tipo IV e que, por isso, ele atua como excelente substrato para o crescimento de células epiteliais da córnea.

O estroma da membrana amniótica possui vários fatores solúveis e inibidores naturais para proteases, além de proteínas antiangiogênicas e antiinflamatórias. Estes fatores propiciam um microambiente livre de inflamação e desempenham funções importantes na comunicação entre o epitélio do limbo e o estroma (GRUETERICH et al., 2003).

PARK \& TSENG (2000) estudaram a ceratectomia fotorefrativa transepitelial na córnea de coelhos e chegaram à conclusão de que a morte dos ceratócitos está associada com a infiltração de células polimorfonucleares na lesão e que o âmnion impede a infiltração destas células, diminuindo, dessa maneira, a morte dos ceratócitos e a inflamação.

SHIMMURA et al. (2001) afirmaram que os linfócitos infiltrados no estroma deste implante sofrem apoptose, constatada após a sua remoção. Afirmaram, ainda, que não é possível saber se ele exerce apoptose nos linfócitos ou se eles passam pelo processo fisiológico de apoptose quando em seu interior. Os mesmos autores constataram que a membrana promove o sequestro de células inflamatórias, funcionando como uma barreira física que protege a superfície ocular destas células.

HAO et al. (2000) identificaram a presença de mRNA para citocinas IL-1RA (receptor antagonista) e IL-10, que são potentes inibidores da inflamação, nas células amnióticas epiteliais e mesenquimais. WOO et al. (2001) afirmaram que a inflamação está ligada ao grau de opacidade da córnea após a sua reparação e que, com a utilização do âmnion, ocorre a diminuição da inflamação, reduzindo esta opacidade.

Em geral, os tecidos imunoprivilegiados como a córnea, os testículos e o útero expressam ligantes e a apoptose dos linfócitos do hospedeiro pode ser induzida por sua junção a eles. Pela imunohistoquímica, já foi constatada a presença de ligantes Fas nas células epiteliais e mesenquimais do estroma amniótico, o que previne sua infiltração por linfócitós (KUBO et al., 2001). LI et al. (2005) também os encontraram em células epiteliais amnióticas humanas cultivadas in vitro e afirmaram que a sua presença previne a inflamação por induzir a apoptose de células Fas-positivas após o implante.

Também foi demonstrado que células epiteliais amnióticas humanas cultivadas in vitro secretam fatores imunossupressivos que inibem a 
resposta imune inata e adaptativa. Esses fatores inibem a migração de neutrófilos e macrófagos também in vitro (LI et al., 2005).

Estimulados pelo relato de um caso, em que uma paciente foi submetida a três implantes com membrana amniótica e apresentou rejeição, WANG et al. (2006) estudaram a imunogenicidade deste tipo de implante a fresco e constataram que ele não é um tecido completamente imunoprivilegiado, mas que possui uma imunogenicidade parcial quando implantado em olho normal de rato e que pode induzir à rejeição em pacientes pré-sensibilizados. Os mesmos autores afirmam que tal material não pode ser considerado não imunogênico apenas pelo fato de secretar fatores antiinflamatórios.

HAO et al. (2000) demonstraram a ação antiangiogênica do âmnion através da expressão da trombospondina-1, um potente antiangiogênico químico, em todas suas células epiteliais e em $20 \%$ de suas células mesenquimais. Além disso, os mesmos autores afirmaram que as suas propriedades antiinflamatórias diminuem o estímulo à angiogênese e, consequentemente, à vascularização corneal.

Em contrapartida, STRAMER et al. (2003) demonstraram que a deposição de tecido fibroso durante a reparação de lesão na córnea está relacionada com a perda da membrana basal epitelial, induzindo à exposição do estroma ao TGF-ß32. No mesmo estudo, sugerem que o efeito de mínima opacidade corneal, ao se utilizar o âmnion como tratamento de úlceras de córnea, deve-se ao fato de sua atuação como membrana basal, impedindo a exposição do estroma ao TGF-ß2.

WOO et al. (2001) pesquisaram os efeitos da membrana humana na reparação de úlceras de córnea em coelhos e concluíram que seu epitélio contém vários fatores solúveis, como o fator de crescimento fibroblástico básico (b-FGF), o EGF, o KGF e o HGF, que atuam facilitando a migração epitelial e promovendo a epitelização. Contudo, foi sugerido que fossem feitas novas pesquisas no intuito de demonstrar os efeitos de sua preservação na viabilidade destes fatores solúveis (SHIMMURA et al., 2001).

KUBO et al. (2001) constataram 50\% de viabilidade celular epitelial na membrana preservada em DMSO a $-80^{\circ} \mathrm{C}$ por dois meses. Essas células também foram capazes de crescer em meio de cultura e apresentaram imunogenicidade quando transplantadas em locais não privilegiados imunologicamente. No mesmo estudo, quando o mesmo tecido preservado foi implantado no meio intracorneal, não houve reação imune, já que a córnea é considerada um tecido imunologicamente privilegiado por não possuir vasos sanguíneos e linfáticos. Para se constatar a imunogenicidade privilegiada do âmnion criopreservado, os autores implantaram pele criopreservada abaixo da cápsula renal, tecido não privilegiado imunologicamente, e verificaram que houve maior invasão de células do hospedeiro neste tecido em comparação com o mesmo procedimento utilizandose o implante criopreservado.

Entretanto, DUA et al. (2004) afirmaram que a membrana amniótica preservada é considerada um tecido inerte com células inviáveis. Relataram ainda que sua habilidade, quando preservada em influenciar a reparação da lesão através de fatores solúveis e citocinas, pode estar muito limitada ou até inexistente.

LEE \& TSENG (1997) teorizaram que a membrana basal espessa e a matriz estromal avascular do âmnion são essenciais para o sucesso do implante. Não verificaram efeitos adversos, como rejeição, nos pacientes que o receberam na forma preservada, pois apenas substrato sem células viáveis foi implantado.

KUBO et al. (2001) afirmaram que a membrana amniótica criopreservada funcionou como uma barreira, impedindo a infiltração de células do hospedeiro quando implantada sob a cápsula renal.

MELLER et al. (2011) citam que o pré tratamento da membrana com ácido e sua posterior secagem a ar leva à perda quase completa das suas propriedades biológicas, resultando na impossibilidade de sua utilização clínica.

PONTES et al. (2008) utilizaram o âmnion da espécie canina, conservada em glicerina $98 \%$ em temperatura ambiente, como bandagem na reparação de lesões superficiais da córnea de coelhos. Os autores notaram formação vascular e retardo no processo de reparação da lesão da córnea em comparação ao grupo não tratado. Nesse estudo, o implante foi preparado segundo as orientações da literatura (KIM \& TSENG, 1995), tendo sido coletado durante operação cesariana eletiva, de forma asséptica, lavado juntamente com o córion utilizando solução de cloreto de sódio $0,9 \%$ estéril, imerso em solução tampão fosfato estéril, contendo $1000 \mathrm{UI} \mathrm{ml}^{-1}$ de penicilina G, $20 \mathrm{mcg} \mathrm{ml}^{-1} \mathrm{de}$ estreptomicina e $2,5 \mathrm{mcg} \mathrm{ml}^{-1}$ de anfotericina $\mathrm{B}$, separado manualmente do córion, estendido sobre papel de nitrocelulose, com sua face epitelial voltada para cima, e cortado no tamanho de $3 \mathrm{~cm}^{2}$. Posteriormente, foi imerso em frasco individual contendo glicerina $99 \%$ e estocado em temperatura ambiente.

Em pesquisa recente (PONTES, 2010), a membrana amniótica bovina, obtida, preparada e conservada da mesma forma descrita acima, foi utilizada 
em camada única no tratamento de perfuração de córneas de coelhos e os resultados foram satisfatórios. Nesse estudo, o âmnion foi suturado diretamente às bordas de uma lesão de $2 \mathrm{~mm}$ de diâmetro e sua reparação aconteceu em todos os animais sem complicações como uveíte ou vascularização da córnea.

$\mathrm{Na}$ experiência clínica dos autores da presente revisão, com a membrana da espécie canina e bovina, notou-se que aquela coletada da última espécie oferece maior resistência à aplicação de suturas e à manipulação por possuir maior espessura. Os autores utilizaram o método descrito por KIM \& TSENG (1995) para a coleta e preparação das membranas, conservando-as em glicerina $98 \%$ e estocando-as em temperatura ambiente por um período mínimo de 30 dias antes de sua utilização, conforme previamente recomendado (KRAUSPENHAR, 2003) para se obter o seu efeito anti-imunogênico e antisséptico. Antes de ser utilizada, realizou-se exame microbiológico para verificar a ocorrência de crescimento fúngico e bacteriano, comprovando-se que o material permanecia sem esses agentes pelo período mínimo de três anos.

Os autores têm aplicado este tipo de implante em úlceras de córnea profundas, na reconstrução da córnea após realização de ceratectomia superficial para remoção de neocrescimentos, de dermóides e de sequestro corneal felino (Figura 1) e verificaram que a reparação da córnea acontece sem complicações, resultando em mínima opacidade. Ainda, condições que estimulam o uso do âmnion na forma descrita são a facilidade de obtenção e manipulação e o baixo custo para a sua conservação.

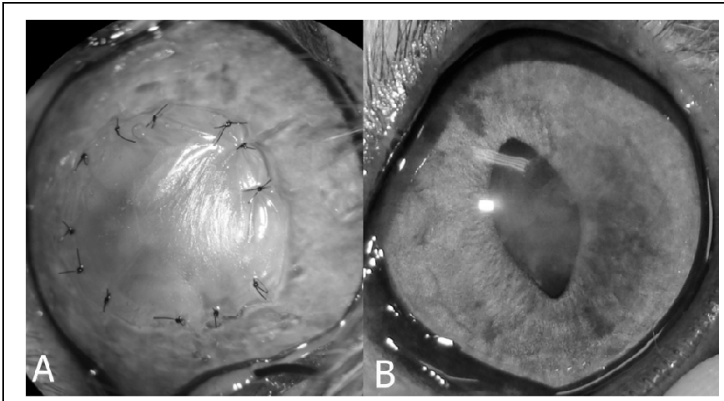

Figura 1 - A - Fotografia da córnea de um gato durante realização de ceratoplastia com membrana amniótica bovina, conservada em glicerina $99 \%$ em temperatura ambiente, após ceratectomia superficial para remoção de sequestro corneal. B - Fotografia do mesmo animal apresentado em A, 120 dias após a realização do procedimento. Nota-se a recuperação quase completa da transparência da córnea. UFV, Viçosa, Brasil, 2011.

\section{CONCLUSÃO}

A membrana amniótica possui propriedades importantes que podem auxiliar no processo de reparação tecidual e que podem ser alteradas em decorrência de sua forma de utilização. Assim, devemse estabelecer quais os objetivos a serem alcançados com o uso de tal implante, a fim de empregá-lo de maneira adequada em cada caso. Nota-se que o uso desse tipo de membrana tem se tornado mais comum na oftalmologia veterinária, entretanto, por apresentar tantas vantagens, acredita-se que ela ainda seja pouco empregada.

\section{AGRADECIMENTOS}

Os autores agradecem à Ophthalmos Indústria Farmacêutica Ltda., pelo apoio concedido aos trabalhos desenvolvidos na área e à Fundação de Amparo à Pesquisa de Minas Gerais (FAPEMIG), pelo financiamento.

\section{REFERÊNCIAS}

AZUARA-BLANCO, A. et al. Amniotic membrane transplantation for ocular surface reconstruction. Brazilian Journal of Ophthalmology, v.83, p.399-402, 1999.

BARROS P.S.M. et al. Amniotic membrane transplantation for the reconstruction of the ocular surface in three cases. Veterinary Ophthalmology, v.8, n.3, p.189-192, 2005. Disponível em: <http:/ /onlinelibrary.wiley.com/doi/10.1111/j.1463-5224.2005.00391.x/ abstract;jsessionid=2B80B6E5D653D2D458907F5C39AFBCC2.d01 t02>. Acesso em: 11 set. 2011. doi: 10.1111/j.1463-5224.2005.00391.x.

BARROS P.S.M. et al. The use of xenologous amniotic membrane to repair canine corneal perforation created by penetrating keratectomy. Veterinary Ophthalmology, v.1, p.119-123, 1998. Disponível em: <http://onlinelibrary.wiley.com/doi/ 10.1046/j.1463-5224.1998.00026.x/abstract>. Acesso em: 11 set. 2011 . doi: 10.1046/j.1463-5224.1998.00026.x.

CARTER, R.T. The role of integrins in corneal wound healing. Veterinary Ophthalmology, v.1, p.2-9; 2009.

CHOI, J.A. et al. Effects of amniotic membrane suspension in the rat alkali burn model. Molecular Vision, v.17, p.404412, 2011.

CREMONINI, D.N. et al. Transplante de membrana amniótica canina criopreservada para cicatrização de córnea com deficiência de células límbicas em coelhos. Arquivo Brasileiro de Medicina Veterinária e Zootecnia, v.59, p.1462-1467, 2007. Disponível em: <http://www.scielo.br/scielo.php?pid=S0102$09352007000600017 \&$ script $=$ sci_arttext $>$. Acesso em: 11 set. 2011. doi: 10.1590/S0102-09352007000600017.

DAYHAW-BARKER, P. Corneal wound healing: I. The players. International Contact Lens Clinic, v.22, p.105-109, 1995a.

DAYHAW-BARKER, P. Corneal wound healing: II. The process. International Contact Lens Clinic, v.22, p.110-116, 1995 b. 
DUA, H.S. et al. The amniotic membrane in ophthalmology. Survey of Ophthalmology, v.49, n.1, p.51-77, 2004.

ENDO, K. et al. Human amniotic membrane, like corneal epithelial basement membrane, manifests the $\alpha_{5}$ - chain of tipe IV collagen. Investigative Ophthalmology and Visual Science, v.45, n.6, p.1771-1774, 2004. Disponível em: <http://www.iovs.org/content/45/6/1771.full>. Acesso em 11 set. 2011. doi: 10.1167/iovs.03-0952.

FINI, M.E. Keratocyte and fibroblast phenotypes in the repairing cornea. Progress in Retinal and Eye Research, v.18, n.4, p.529-551, 1999. Disponível em: <http:// www.sciencedirect.com/science/article/pii/ S1350946298000330>. Acesso em 11 set. 2011. doi: 10.1016/ S1350-9462(98)00033-0.

GELATT, K.N. Doenças e cirurgia da córnea e esclera do cão. In: ___ Manual de oftalmologia veterinária. São Paulo: Manole, 2003. Cap.7, p.125-164.

GRIERSON, L. et al. Hepatocyte growth factor/scatter factor in the eye. Progress in Retinal and Eye Research, v.19, p.779802, 2000. Disponível em: <http://www.ncbi.nlm.nih.gov/ pubmed/11029554>. Acesso em: 11 set. 2011. doi:10.1016/ S1350-9462(00)00015-X.

GRUETERICH, M. et al. Ex vivo expansion of limbal epithelial stem cells: amniotic membrane serving as a stem cell niche. Survey of Ophthalmology, v.48, n.6, p.631-646, 2003. Disponível em: <http://www.ncbi.nlm.nih.gov/pubmed/11029554>. Acesso em 11 set. 2011. doi: 10.1016/j.survophtha1.2003.08.003.

$\mathrm{HAO}$, Y. et al. Identification of antiangiogenic and antiinflamatory proteins in human amniotic membrane. Cornea, v.19, p.348352, 2000. Disponível em: <http://www.ncbi.nlm.nih.gov/pubmed/ 10832697>. Acesso em 10 out. 2010.

IMANISHI, J. et al. Growth factors: importance in wound healing and maintenance of transparency of the cornea. Progress in Retinal and Eye Research, v.19, n.1, p.113129, 2000. Disponível em: <http://www.ncbi.nlm.nih.gov/ pubmed/10614683>. Acesso em: 11 set. 2011. doi:10.1016/ S1350-9462(99)00007-5.

KERN, T.J. Ulcerative keratitis. Veterinary Clinics of North American: Small Animal Practice, v.20, n.3, p.643-666, 1990.

KIM, J.C.; TSENG, S.C.G. Transplantation of preserved human amniotic membrane for surface reconstruction in severely damaged rabbit corneas. Cornea, v.14, n.5, p.473-484, 1995.

KIM, J.Y. et al. Effect of bovine freeze-dried amniotic membrane (Amnisite-BA ${ }^{\mathrm{TM}}$ ) on uncomplicated canine corneal erosion. Veterinary Ophthalmology, v.12, n.1, p.36-42, 2009. Disponível em: <http://onlinelibrary.wiley.com/doi/ 10.1111/j.1463-5224.2009.00671.x/abstract>. Acesso em: 11 set. 2011. doi: 10.1111/j.1463-5224.2009.00671.x.

KLENKLER, B.; SHEARDOWN, H. Growth factors in the anterior segment: role in tissue maintenance, wound healing and ocular pathology. Experimental Eye Research, v.79, p.677688, 2004. Disponível em: <http://www.ncbi.nlm.nih.gov/ pubmed/15500826>. Acesso em: 11 set. 2011. doi: 10.1016/ j.exer.2004.07.008
KUBO, M. et al. Immunogenicity of human amniotic membrane in experimental xenotransplantation. Investigative Ophthalmology and Visual Science, v.42, n.7, p.15391546, 2001. Disponível em: <http://www.iovs.org/cgi/content/ full/42/7/1539>. Acesso em: 10 out. 2010.

LEE, S.; TSENG, S.C.G. Amniotic membrane transplantation for persistent epithelial defects with ulceration. American Journal of Ophthalmology, v.123, n.3, p.123-303, 1997. Disponível em: 〈http://www.ncbi.nlm.nih.gov/pubmed>. Acesso em: 10 out. 2010.

LI, H. et al. Immunosuppressive factors secreted by human amniotic epithelial cells. Investigative Ophthalmology and Visual Science, v.46, n.3, p.900-907, 2005. Disponível em: <http://www.iovs.org/content/46/3/900.short>. Acesso em: 11 set. 2011. doi: 10.1167/iovs.04-0495.

MÁRQUEZ, E.B. et al. Epidermal growth factor receptor in corneal damage: update and new insights from recents reports. Cutaneous and Ocular Toxicology, v.30, n.1, p.7-14, 2011.

MELLER, D. et al. Amniotic membrane transplantation in the human eye. Deutsches Ärzteblatt International, v.108, n. 14, p.243-248, 2011.

MICHELACCI, Y.M. Collagens and proteoglycans of the corneal extracellular matrix. Brazilian Journal of Medical and Biological Research, v.36, p.1037-1046, 2003. Disponível em: <http://www.ncbi.nlm.nih.gov/pubmed/12886457>. Acesso em: 11 set. 2011. doi: 10.1590/S0100-879X2003000800009.

PARK, J.H. et al. Clinical efficacy of amniotic membrane transplantation in the treatment of various ocular surface diseases. Contact Lens and Anterior Eye, v.31, n.2., p.7380, 2008. Disponível em: <http://www.ncbi.nlm.nih.gov/ pubmed/18249149>. Acesso em: 11 set. 2011. doi:10.1016/ j.clae.2007.11.004.

PARK, W.C.; TSENG, S.C.G. Modulation of acute inflammation and keratocyte death by suturing, blood, and amniotic membrane in PRK. Investigative Ophthalmology and Visual Science, v.41, n.10, p.2906-2914, 2000.

PONTES, K.C.S. Membrana amniótica xenógena, associada ou não ao n-butil 2-cianoacrilato, no tratamento de lesão corneal perfurada. Estudo experimental em coelhos. 2010. 93f. Tese (doutorado em Medicina Veterinária) - Curso de Pósgraduação em Medicina Veterinária, Universidade Federal de Viçosa, MG

PONTES, K.C.S. et al. Membrana amniótica bovina, preservada em glicerina, no tratamento de úlcera de córnea em um cão e de sequestro corneal em dois felinos - Relato de casos. Revista Clínica Veterinária, n.85, p.88-96, 2010.

PONTES, K.C.S. et al. Membrana amniótica canina utilizada como bandagem em úlcera superficial de córnea de coelhos Aspectos clínicos. Arquivo Brasileiro de Medicina Veterinária e Zootecnia, v.60, n.5, p.1069-1074, 2008. Disponível em: <http://www.scielo.br/scielo.php?pid=S0102$09352008000500005 \&$ script $=$ sci_arttext $>$. Acesso em: 11 set. 2011. doi: 10.1590/S0102-09352008000500005.

SHAO, C. et al. Suppression of corneal neovascularization by PEDF release from human amniotic membrane. Investigative 
Ophthalmology and Visual Science, v.45, n.6, p.17581762, 2004. Disponível em: <http://www.iovs.org/content/45/ 6/1758.full>. Acesso em: 11 set. 2011. doi: 10.1167/iovs.030882 .

SHEHA, H. et al. Sutureless amniotic membrane transplantation fo severe bacterial keratitis. Cornea, v.28, n.10, p.11181123, 2009. Disponível em: <http://www.ncbi.nlm.nih.gov/ pubmed/19770726>. Acesso em: 11 set. 2011. doi: 10.1097/ ICO.0b013e318112abad.

SHIMMURA, M.D. et al. Antiinflamatory effects of amniotic membrane transplantation in ocular surface disorders. Cornea, v.20, n.4, p.408-413, 2001. Disponível em: <http:// www.ncbi.nlm.nih.gov/pubmed/11333331>. Acesso em: 10 out. 2010 .

SHIMMURA, M.D. et al. Antiinflamatory effects of amniotic membrane transplantation in ocular surface disorders. Cornea, v.20, n.4, p.408-413, 2001. Disponível em: <http:/ /www.ncbi.nlm.nih.gov/pubmed/11333331>. Acesso em: 10 out. 2010 .

SLATTER, D.; DIETRICH, U. Córnea e esclera. In: SLATTER, D. Manual de cirurgia de pequenos animais. São Paulo: Manole, 2007. Cap.91, p.1368-1396.

STARTUP, F.G. Corneal ulceration in dog. Journal of Small Animal Practice, v.25, n.12, p.737-752, 1984.

STRAMER, B.M. et al. Molecular mechanisms controlling the fibrotic repair phenotype in cornea: implications for surgical outcomes. Investigative Ophthalmology and Visual Science, v.44, n.10, p.4237-4246, 2003. Disponível em: <http://www.iovs.org/content/44/10/4237.abstract>. Acesso em: 11 set. 2011 . doi: 10.1167/iovs.02-1188.

TANDON, A. et al. Role of transforming growth factor beta in corneal function, biology and pathology. Current Molecular Medicine, v.10, n.6, 565-578, 2011.
WANG, M. et al. Immunogenicity and antigenicity of allogeneic amniotic epithelial transplants grafted to the cornea, conjunctiva and anterior chamber. Investigative Ophthalmology and Visual Science, v.47, n.4, p.1522-1532, 2006. Disponível em: 〈http://www.ncbi.nlm.nih.gov/pubmed/16565388>. Acesso em: 11 set. 2011. doi: 10.1167/iovs.05-0787.

WATSKY, M.A. et al. New insights into the mechanism of fibroblast to myofibroblast transformation and associated pathologies. International Review of Cell and Molecular Biology, v.282, p.165-192, 2010.

WILCOCK, B. General pathology of the eye. In: SLATTER, D. Slatter's fundamentals of veterinary ophthalmology. 4.ed. Philadelphia: Saunders Elsevier, 2008. Cap.4, p.62-80.

WILCOCK, B.P. The eye and ear. In: JUBB, K.V.F. et al. Pathology of domestic animals. 4.ed. London: Academic, 1993. Cap.4, p.461-464.

WILKIE, D.A.; WHITTAKER, C. Surgery of the cornea. Veterinary Clinics of North American: Small Animal Practice, v.27, n.5, p.1067-1107, 1997.

WILSON, S.E. et al. Epidermal growth factor, transforming growth factor alpha, transforming growth factor beta, acidic fibroblastic growth factor, basic fibroblastic growth factor, and interleukin-1 proteins in the cornea. Experimental Eye Research, v.59, p.63-72, 1994.

WOO, H-M. et al. Effects of amniotic membrane on epithelial wound healing and stromal remodeling after excimer laser keratectomy in rabbit cornea. Brazilian Journal of Ophthalmology, v.85, n.3, p.345-349, 2001. Disponível em: <http://www.ncbi.nlm.nih.gov/pmc/articles/PMC1723894/>. Acesso em: 11 set. 2011. doi: 10.1136/bjo.85.3.345.

YU, F.S. et al. Growth factors and corneal epithelial wound healing. Brain Research Bulletin, v.81, n.2-3, p.229-235, 2010. 